\title{
Major Depression with Ischemic Heart Disease: Effects of Paroxetine and Nortriptyline on Measures of Nonlinearity and Chaos of Heart Rate
}

\author{
Vikram K. Yeragania Steven Roose ${ }^{b}$ Mallika Mallavarapuc \\ R.K.A. Radhakrishna ${ }^{a}$ Vanessa Pesce ${ }^{b}$ \\ aDepartment of Psychiatry and Behavioral Neurosciences, Wayne State University School of Medicine, \\ Detroit, Mich., and ' ${ }^{\text {Department }}$ of Psychiatry, Columbia University School of Medicine, New York, N.Y., USA; \\ 'Bangalore University, and dDepartment of ECE, Indian Institute of Science, Bangalore, India
}

\section{Key Words \\ Major depression - Cardiovascular mortality • \\ Nonlinearity · Chaos · Largest Lyapunov exponent · Heart rate variability $\cdot$ Awake $\cdot$ Sleep}

\begin{abstract}
Depression is associated with increased cardiovascular mortality in patients with preexisting cardiac illness. A decrease in cardiac vagal function as suggested by a decrease in heart rate variability (HRV) or heart period variability has been linked to sudden death in patients with cardiac disease as well as in normal controls. Recent studies have shown decreased vagal function in cardiac patients with depression as well as in depressed patients without cardiac illness. In this study, we compared $20 \mathrm{~h}$ awake and sleep heart period nonlinear measures using quantification of nonlinearity and chaos in two groups of patients with major depression and ischemic heart disease (mean age 59-60 years) before and after 6 weeks of treatment with paroxetine or nortriptyline. Patients received paroxetine, 20-30 mg/day or nortriptyline targeted to $190-570 \mathrm{nmol} / \mathrm{l}$ for 6 weeks. For HRV analysis, 24 patients were included in the paroxe-
\end{abstract}

\begin{tabular}{|c|c|}
\hline KARGER & $\begin{array}{l}\text { (C) } 2002 \text { S. Karger AG, Basel } \\
0302-282 X / 02 / 0463-0125 \$ 18.50 / 0\end{array}$ \\
\hline $\begin{array}{l}\text { Fax + } 41613061234 \\
\text { E-Mail karger@karger.ch } \\
\text { www.karger.com }\end{array}$ & $\begin{array}{l}\text { Accessible online at: } \\
\text { www. karger.com/nps }\end{array}$ \\
\hline
\end{tabular}

tine treatment study and 20 patients in the nortriptyline study who had at least 20,000 s of awake data. The ages of these groups were $60.4 \pm 10.5$ years for paroxetine and $60.8 \pm 13.4$ years for nortriptyline. There was a significant decrease in the largest Lyapunov exponent (LLE) after treatment with nortriptyline but not paroxetine. There were also significant decreases in nonlinearity scores on $S_{\text {netPR }}$ and $S_{\text {netGs }}$ after nortriptyline, which may be due to a decrease in cardiac vagal modulation of HRV. $S_{\text {netGs }}$ and awake LLE were the most significant variables that contributed to the discrimination of postparoxetine and postnortriptyline groups even with the inclusion of time and frequency domain measures. These findings suggest that nortriptyline decreases the measures of chaos probably through its stronger vagolytic effects on cardiac autonomic function compared with paroxetine, which is in agreement with previous clinical and preclinical reports. Nortriptyline was also associated with a significant decrease in nonlinearity scores, which may be due to anticholinergic and/or sympatholytic effects. As depression is associated with a strong risk factor for cardiovascular mortality, one should be careful about using any drug that adversely affects cardiac vagal function.

Dr. Vikram K. Yeragani, Professor of Psychiatry

Wayne State University School of Medicine

Flat No. 16, K.C.N. Mansion, Madhava Nagar

Bangalore 560001 (India)

Tel. +91 80 2287715, Fax +91 80 3610085, E-Mail vikramyershr@yahoo.com 


\section{Introduction}

Major depression is associated with poor prognosis in patients with heart disease [1-9]. Some studies have shown decreased heart rate variability (HRV) in these vulnerable patients with and without overt cardiac disease using linear and nonlinear techniques [10-13]. Roose et al. $[14,15]$ have found that nortriptyline, a tricyclic antidepressant, was associated with a higher rate of side effects compared with paroxetine, a serotonergic reuptake inhibitor in depressed patients with heart disease. Our previous reports on time and frequency domain measures of HRV in patients with anxiety after treatment with imipramine, paroxetine and nortriptyline have shown that nortriptyline as well as paroxetine were associated with a significant decrease in high frequency (HF: 0.15$0.5 \mathrm{~Hz}) \mathrm{HRV}$, though there was an increase in beat-tobeat QT interval variability only in the nortriptyline group, which suggests a relative increase in sympathetic function and a decrease in cardiac vagal modulation after treatment with nortriptyline [16-19]. The mean age group of these patients was around 35 years and they did not have a history of any heart disease.

An increase in cardiac sympathetic function or a decrease in vagal function can lead to serious ventricular arrhythmias and sudden death [20]. Recent noninvasive techniques on HRV and QT variability show a great deal of promise to study cardiac autonomic function in different disorders and also to evaluate the effects of various drugs [21-29].

Our findings on short-term and 24-hour HRV and measures of nonlinearity and chaos suggest that patients with depression and no heart disease have a significantly decreased largest Lyapunov exponent (LLE) and also decreased spectral power in different bands from 0 to $0.5 \mathrm{~Hz}$ of HR time series [12,13]. This is important in view of the strong association between decreased HRV and significant cardiovascular mortality in patients with cardiac disease, depression, anxiety, and also normal controls [30-33]. Using frequency domain measures, HR time series can usually be decomposed into very low frequency (VLF: 0-0.04 Hz), low frequency (LF: 0.04$0.15 \mathrm{~Hz}$ ) and high frequency (HF: $0.15-0.5 \mathrm{~Hz}$ ) bands [34-36]. VLF power appears to be related to thermoregulation and vascular mechanisms, LF power to sympathetic as well as parasympathetic influences and HF power to parasympathetic mechanisms.

Several investigators have pointed out and have demonstrated the nonlinear nature of the HR or heart period (HP) time series and have also shown the superiority or the additional utility of these measures to the traditionally used time and frequency domain measures [37-48]. Several recent studies have stressed the importance of nonlinear measures compared with the time and frequent domain measures of HR or HP. Poon and Merrill [49] reported a decrease in cardiac chaos in severe congestive heart failure, a condition associated with sudden death. Voss et al. [50] showed that nonlinear measures seem to be a better predictor of high arrhythmia risk than just the global HRV, using multiparametric analysis. Makikallio et al. [51] showed that fractal analysis of HR could be used as a predictor of mortality in patients with depressed left ventricular function after acute myocardial infarction. Huikuri et al. [52] and Huikuri and Makikallio [53] discussed time and frequency domain, and nonlinear measures in their reports suggesting that the nonlinear measures of HRV are promising tools to stratify risk and as predictors of death and life-threatening arrhythmia in postinfarction populations. Thus, there is mounting evidence to suggest that the nonlinear measures are clinically very important.

Previous studies have suggested that tricyclic antidepressants result in tachycardia, prolongation of QTc interval, decreased HRV and an increase in QT variability [19, $54,58]$, which are all associated with significant cardiovascular events. Rechlin et al. [59] have shown that amitriptyline significantly decreases HRV in patients with depression. On the other hand, Tucker et al. [60] have reported that paroxetine increased cardiac vagal activity in patients with panic disorder.

Thus, it is important to understand the effects of various antidepressant drugs on cardiac autonomic function in various age groups of patients using these novel noninvasive techniques. In this study, we sought to investigate the effects of paroxetine and nortriptyline in patients with major depression and ischemic heart disease aged about 60 years using HPV and Holter ECG records that were obtained in a previous treatment study [61]. In the original study, Roose et al. [61] have found that $61 \%$ of patients on paroxetine and $55 \%$ on nortriptyline improved after treatment. There was no significant change in blood pressure or conduction intervals on ECG with either drug. Paroxetine had no sustained effects on HR or rhythm. However, nortriptyline produced a significant increase in HR and a decrease in standard deviation (SD) of all normal R-R intervals. Nortriptyline produced adverse cardiac events in $18 \%$ of patients compared with only $2 \%$ of patients in the paroxetine group. In our recent study [62] on spectral measures and two nonlinear measures, fractal dimension and measures of symbolic dy- $\overline{126}$ Neuropsychobiology 2002;46:125-135
Yeragani/Roose/Mallavarapu/

Radhakrishna/Pesce 
namics in the above group of patients, nortriptyline was associated with significant vagolytic effects compared with paroxetine. We also found that paroxetine increases HR time series complexity as suggested by WC-100, one of the measures of symbolic dynamics. In the present study, we have specifically studied the measures of nonlinearity and chaos, which is quantified by obtaining the LLE before and after treatment with paroxetine and nortriptyline. We hypothesized that nortriptyline treatment would result in a significant decrease in the LLE in HR time series.

\section{Subjects and Methods}

\section{Subjects}

Original Study Design. This study was conducted in four university research centers [61], and was approved by the Internal Review Boards at all 4 sites for the protection of subjects. The inclusion criteria were the DSM-IV criteria for major depressive disorder, unipolar subtype with a score of 16 or more on the 17-item Hamilton Rating Scale for Depression (HAMD) [63], have ischemic heart disease and be capable and willing to sign an informed consent to participate in this study aimed at the cardiovascular safety of antidepressant medication. Patients were considered to have ischemic heart disease if they had a myocardial infarction, coronary artery bypass graft surgery, coronary angioplasty, a positive stress test, or angiographic evidence of a $75 \%$ or greater luminal narrowing of a major coronary artery or one of its primary branches. Patients were excluded if the myocardial infarction occurred within 3 months prior to their recruitment, with a baseline QTc of $460 \mathrm{~ms}$ or more, unstable or crescendo angina and if they were receiving drugs with class I antiarrhythmic activity or warfarin.

After they had signed the informed consent, during a 2-week placebo period, baseline cardiac testing was conducted including a 24hour continuous Holter ECG record, as well as a routine 12-lead ECG at the beginning and end of the placebo period. If the patients had completed with the study procedures and continued to meet inclusion and exclusion criteria at the end of the placebo period, they were randomized by permuted blocks of 10 to treatment with either paroxetine or nortriptyline for a double-blind 6-week trial.

Dosing. Patients less than 65 years of age received an initial dose of paroxetine of $20 \mathrm{mg}$ per day for the first 3 weeks, whereas older patients were started at $10 \mathrm{mg}$ per day for the first week and then the dose was increased to $20 \mathrm{mg} /$ day for the next 2 weeks. At the end of 3 weeks, if they did not show a 50\% decrease in HAMD scores, paroxetine was increased to $30 \mathrm{mg}$ at week 4 and, if necessary, to $40 \mathrm{mg}$ at the end of week 5 . The nortriptyline dose was begun at $25 \mathrm{mg}$, which was increased to $50 \mathrm{mg}$ by day 3 . On the 7 th day, the plasma level was measured and the dose adjusted to achieve a plasma nortriptyline level of 304 and $456 \mathrm{nmol} / 1$. The idea was to have the dose within the therapeutic range of $190-570 \mathrm{nmol} / 1(50-150 \mathrm{ng} / \mathrm{ml})$. Medication compliance was monitored by weekly pill counts in addition to plasma level measurements in blood samples that were also taken from patients on paroxetine.

Drug Discontinuation. Drug discontinuation was done due to an adverse cardiac event, if there was a greater than $50 \%$ increase in the
QRS interval from baseline, QRS interval exceeded $180 \mathrm{~ms}$ in patients with a bundle-branch block at baseline, the QTc interval exceeded $500 \mathrm{~ms}$ and if the patient developed a proarrhythmic effect. Additional things that were taken into account were significant blood pressure changes, cardiac enzyme levels and 24-hour ECG.

Cardiac Assessment. As stated above, 24-hour ECG was obtained before and after 2 weeks of placebo administration. Patients received active medication for 6 weeks. Twenty-four-hour ECGs were then repeated at the end of 2 and 6 weeks of medication treatment. Thus, complete data included four 24-hour ECG records.

The mean \pm SD for paroxetine dose was $22 \pm 5 \mathrm{mg}$ /day, and 74 $\pm 30 \mathrm{mg}$ /day for nortriptyline. At week 6 , the nortriptyline levels were within the therapeutic range. In the original sample, 37/41 $(90 \%)$ of patients treated with paroxetine completed the trial and 25 $(68 \%)$ were responders. Sixty-five percent (26/40) completed the nortriptyline trial and $22(85 \%)$ were responders.

\section{Present Study on Measures of HRV}

This study included only those patients who had at least $20,000 \mathrm{~s}$ of data during the awake period and who had a pretreatment record, which was a preplacebo record, and a second one 6 weeks after treatment. Many patients did not have all four and that is the reason why we had to limit our analyses to two records only. However, we compared pre- and postplacebo lead-in records and found no significant difference in any of our HRV measures. One other reason to exclude the 2-week posttreatment record was that the effects of the drugs might not have been observable by then. Twenty-four patients were included in the paroxetine treatment study and 20 patients in the nortriptyline study. We have used means and SD throughout the text and tables of this paper. Thirty-three patients had 20-hour data, 44 had awake data and 30 sleep data.

Twenty-four-hour ECG was recorded using cassette tapes, was digitized by a Marquette 8,000 scanner, and QRS labeling and editing was done using standard Marquette algorithms. Then, the ASCII files of R-R intervals in milliseconds were edited according to previous techniques described in detail [64-67]. These data were edited using software which eliminated any premature ventricular beats. This method was similar to the one used by Huikuri et al. [64]. An $\mathrm{R}-\mathrm{R}$ interval was interpreted as a premature beat if it deviated from a previous qualified interval by more than a tolerance level of $30 \%$. These data were eliminated and the resulting gaps were filled with an average value in the immediate neighborhood. The edited time series were then sampled at $2 \mathrm{~Hz}$ using the technique described by Berger et al. [68], to obtain the instantaneous HR. This stepwise continuous instantaneous HR signal maintains an amplitude equal to the reciprocal of the R-R interval and the convolution of the HR signal with the rectangular window has the effect on the power spectrum of multiplication by a low-pass filter. A $2-\mathrm{Hz}$ sampling rate would allow an accurate estimation of the power spectrum up to $0.5 \mathrm{~Hz}$, which is equivalent to a breathing rate of $30 / \mathrm{min}$. From here on, all the data were converted to R-R interval time series $[60,000 / \mathrm{HR}$ in beats per minute (bpm)]. Then, the data were detrended using a linear detrending technique prior to the other analyses except for the nonlinear analyses.

\section{Spectral Analysis}

The power spectrum was obtained as the magnitude squared of the Fourier transform using a rectangular data window. The powers were integrated in the following bands: total power (TP, $0-0.5 \mathrm{~Hz}$ ), ultra-low frequency power (ULF, 0-0.0033 Hz), VLF (0.0033- 
$0.04 \mathrm{~Hz}), \mathrm{LF}(0.04-0.15 \mathrm{~Hz})$ and HF $(0.15-0.5 \mathrm{~Hz})$. For spectral analysis, we used 20-hour data, and awake and sleep data of 20,000 s of duration. These data had been presented in our previous report [62]. We used awake and sleep spectral powers in ULF, VLF, LF and $\mathrm{HF}$ bands for entering into discriminant function analysis and multiple regression analysis in addition to the nonlinear measures to compare the paroxetine and nortriptyline groups after treatment.

\section{Nonlinear Analyses}

The methods have been described in great detail in our previous reports [13, 44-46], and are described here again in some detail. The reconstruction of $\mathrm{HR}$ time series and the calculation of the minimum embedding dimension (MED), the LLE and nonlinearity scores were all computed using a PC with custom-designed software according to the following methods.

\section{Time Delay Embedding and Attractor Reconstruction}

The first step in nonlinear dynamical analysis is the reconstruction of an attractor in phase-space; since we do not know a priori the coordinates of the phase-space, it is necessary to derive them from observed time series.

\section{Estimation of MED}

The proper reconstruction of an attractor is guaranteed if the dimension of phase-space is sufficient to unfold the attractor. It is shown that an embedding dimension of $m \geq 2 d+1$ can achieve this, where $d$ is the dimension of the attractor [69]. In most cases of observed time series analysis, we neither have knowledge of $d$ nor of $m$. There are many different algorithms used in the estimation of these quantities [70-74], but many of them have the disadvantage of either being too subjective, requiring a large number of data points or being computationally very intensive. The method proposed by Cao [75] overcomes these difficulties and is suitable for short-term time series. Additionally, this method gives more reliable estimates of MED, even when the dimension is sufficiently large.

Another quantity is determined which is useful in distinguishing deterministic signals from stochastic signals and it is given by

$$
E^{*}(m)=\frac{1}{N-m \tau} \sum_{t=1}^{N-m \tau}\left|x_{i+m \tau}-x_{n(i, m)+m \tau}\right|
$$

and its variation from $m$ to $m+1$ as

$$
E 2(m)=E^{*}(m+1) / E^{*}(m)
$$

where $n(i, m)$ has the same meaning defined earlier (equation 1). For random time series, $E 1(m)$ will never attain a saturation value as $m$ is increased, but because of limited data samples and practical computations, it may be difficult to ascertain whether $E 1(\mathrm{~m})$ is slowly changing or has stopped changing. In such a situation, $E 2(m)$ will be very useful, since for random data, future values are independent of past values. $E 2(m)$ will be equal to 1 for any $m$, whereas for deterministic signals, there exist some values of $m$ such that $E 2(m) 1$. We computed both $E 1(m)$ and $E 2(m)$.

This method was applied on time series of some of the standard maps and we found their MED tallying with the literature.

\section{Subjectivity of Arriving at MED}

Though it is a cause for some concern when the MEDs are calculated by many people, this can be substantially reduced by training only a few people to do so, and in this particular paper, one of the authors who was blind to the patients' condition has calculated all the MED. We chose the point of the beginning of saturation on the graph after plotting the $E 1$ values.

\section{Largest Lyapunov Exponent}

We used the method of Rosenstein et al. [76] to calculate the LLE. Lyapunov exponents (LEs) are another invariant, which could be used to characterize the dynamical system. It quantifies sensitivity of the system to initial conditions. An $m$-dimensional dynamical system has $m$ LEs. The presence of a positive LE indicates chaos. It also quantifies the amount of instability or predictability of the system. A fully deterministic system will have a zero LE since it is fully predictable, whereas a random system will have a large positive exponent indicating no predictability. In most applications, it is sufficient to compute only the LLE instead of all LEs. There are many algorithms available to estimate the LLE and the Lyapunov spectrum [77-80]. Most of them are unreliable when operated on small data sets. In our present work, we used the method proposed by Rosenstein et al. [76] which is robust against small data length [76].

In practice, the LE is easily and accurately estimated using a leastsquare fit to the 'average' line defined by

$$
\gamma(n)=\frac{1}{\Delta t}\left\langle\ln d_{i}(n)\right\rangle
$$

where \langle\rangle denotes the average over all values of $i$. This last averaging step is the main feature that allows an accurate evaluation of $\lambda$ even when we have a short and noisy data set.

\section{Tests for Nonlinearity}

The erratic fluctuations that are observed in an experimental time series owe their dynamical variation to a mix of various influences: chaos, nonchaotic but still nonlinear determinism, linear correlation and noise, both in the dynamics and in the measuring setup. This emphasizes the need for estimating the nonlinear structure in the time series. In our present work, we investigated the nonlinear structure present with HRV time series using two methods, and we checked whether nonlinear time correlations were present among the time series values. Both methods are based on the analysis of the extrema (local maxima or minima) as proposed by Di Garbo et al. [81].

\section{Nonlinearity Test Based on Extrema of a Time Series}

It has been shown that the dynamical behavior of the real time solution of an ordinary differential equation is strongly connected to its analytic properties in the complex time plane, and in particular to the distribution of the singularities nearest to the real axis [82]. The second consideration arises from a general property of a stochastic process, which states that given a mean square differentiable stochastic process, $x(t)$, the expected number of its extrema for unit time is contained in the joint density function of $x(t), x(t)$ and $x \cdot(t)$ [83]. These theoretical and numerical results suggest that the sequence of extrema of a time series contains dynamical information of the process generating them. Both methods statistically discriminate measures which are evaluated based on extremas for original and surrogate data sets.

Two types of surrogates are considered in our analysis, Fourier shuffled (GS) and phase randomized (PR) surrogates.
Yeragani/Roose/Mallavarapu/

Radhakrishna/Pesce 
Table 1. Nonlinear measures of HP before and after treatment

\begin{tabular}{|c|c|c|c|c|}
\hline & \multicolumn{2}{|l|}{ Paroxetine } & \multicolumn{2}{|l|}{ Nortriptyline } \\
\hline & predrug & postdrug & predrug & postdrug \\
\hline \multicolumn{5}{|l|}{$20 \mathrm{~h}$} \\
\hline R-R mean & $839.04 \pm 122.82$ & $868.89 \pm 126.70$ & $825.53 \pm 152.34$ & $736.24 \pm 133.06^{*}$ \\
\hline R-R SD & $111.44 \pm 41.04$ & $111.47 \pm 36.11$ & $112.50 \pm 65.68$ & $101.24 \pm 43.47$ \\
\hline $\mathrm{S}_{\mathrm{pscGS}}$ & $1.76 \pm 0.48$ & $2.03 \pm 0.40$ & $1.90 \pm 0.50$ & $1.95 \pm 0.39$ \\
\hline $\mathrm{S}_{\mathrm{psc} P R}$ & $3.13 \pm 1.40$ & $4.18 \pm 2.69$ & $3.05 \pm 1.11$ & $3.22 \pm 1.38$ \\
\hline $\mathrm{S}_{\text {netGS }}$ & $5.52 \pm 2.02$ & $6.47 \pm 1.62$ & $6.19 \pm 1.96$ & $4.64 \pm 1.44 * * *$ \\
\hline $\mathrm{S}_{\text {netPR }}$ & $4.93 \pm 2.13$ & $6.41 \pm 1.72$ & $5.61 \pm 2.29$ & $4.16 \pm 1.81^{* * *}$ \\
\hline MED & $13.11 \pm 1.26$ & $12.76 \pm 1.36$ & $12.95 \pm 1.78$ & $13.55 \pm 0.88$ \\
\hline LLE & $0.10 \pm 0.01$ & $0.11 \pm 0.02$ & $0.11 \pm 0.11$ & $0.09 \pm 0.013^{*}$ \\
\hline \multicolumn{5}{|l|}{ Awake } \\
\hline R-R mean & $788.85 \pm 123.92$ & $836.37 \pm 110.26$ & $823.61 \pm 148.47$ & $719.31 \pm 123.20 *$ \\
\hline R-R SD & $86.91 \pm 40.75$ & $87.40 \pm 25.49$ & $96.21 \pm 50.77$ & $65.70 \pm 26.71^{*}$ \\
\hline $\mathrm{S}_{\mathrm{pscGS}}$ & $1.83 \pm 0.61$ & $2.26 \pm 0.66$ & $2.14 \pm 0.61$ & $2.19 \pm 0.74$ \\
\hline $\mathrm{S}_{\mathrm{psc} P R}$ & $3.59 \pm 2.66$ & $3.64 \pm 2.87$ & $3.66 \pm 3.41$ & $4.07 \pm 2.23$ \\
\hline $\mathrm{S}_{\text {netGS }}$ & $5.42 \pm 2.27$ & $5.95 \pm 1.6$ & $5.99 \pm 2.40$ & $4.2 \pm 1.9^{* * *}$ \\
\hline$S_{\text {netPR }}$ & $4.93 \pm 2.42$ & $5.6 \pm 2.0$ & $6.08 \pm 3.89$ & $3.6 \pm 2.1^{* * *}$ \\
\hline MED & $13.30 \pm 1.58$ & $12.45 \pm 1.31$ & $13.08 \pm 1.75$ & $13.16 \pm 1.22$ \\
\hline LLE & $0.11 \pm 0.02$ & $0.11 \pm 0.01$ & $0.11 \pm 0.01$ & $0.10 \pm 0.01^{* *}$ \\
\hline \multicolumn{5}{|l|}{ Sleep } \\
\hline R-R mean & $931.85 \pm 124.98$ & $999.47 \pm 139.52$ & $931.32 \pm 246.03$ & $857.40 \pm 140.98$ \\
\hline R-R SD & $87.36 \pm 26.84$ & $82.49 \pm 20.63$ & $90.66 \pm 41.37$ & $75.07 \pm 35.49$ \\
\hline $\mathrm{S}_{\mathrm{pscGS}}$ & $1.81 \pm 0.71$ & $1.83 \pm 0.58$ & $1.66 \pm 0.60$ & $1.74 \pm 0.35$ \\
\hline $\mathrm{S}_{\mathrm{pscPR}}$ & $2.92 \pm 1.31$ & $4.40 \pm 4.59$ & $2.69 \pm 0.95$ & $2.90 \pm 2.84$ \\
\hline $\mathrm{S}_{\text {netGS }}$ & $5.75 \pm 1.90$ & $7.1 \pm 1.9$ & $6.36 \pm 1.84$ & $5.2 \pm 2.2^{* * *}$ \\
\hline $\mathrm{S}_{\text {netPR }}$ & $5.13 \pm 2.15$ & $6.7 \pm 2.1$ & $5.60 \pm 2.05$ & $4.6 \pm 2.5^{* *}$ \\
\hline MED & $13.08 \pm 1.35$ & $12.90 \pm 1.64$ & $12.80 \pm 1.98$ & $13.59 \pm 1.11$ \\
\hline LLE & $0.10 \pm 0.01$ & $0.11 \pm 0.02$ & $0.11 \pm 0.02$ & $0.09 \pm 0.01 *$ \\
\hline
\end{tabular}

$* \mathrm{p}<0.025 ; * * \mathrm{p}<0.01 ; * * * \mathrm{p}<0.005$. Significant difference between the posttreatment values of the paroxetine and nortriptyline groups (Student's t test, two-tailed). R-R mean and SD are milliseconds.

\section{Pattern of Singularities in the Complex Time Plane Algorithm}

The steps involved in quantifying nonlinear correlations with the pattern of singularities in the complex time plane (PSC) method are:

(1) determine the couples $\left\{s_{t}, t_{j}\right.$ for $\left.j=1,2, \ldots, n\right\}$ corresponding to local maxima and time at which it occurred;

(2) determine the length of the broken line joining these extremas,

$$
L=\sqrt{\sum_{j=1}^{n-1}\left\{\left(S_{t_{j+1}}-S_{t_{j}}\right)^{2}+\left(t_{j+1}-t_{j}\right)^{2}\right\}}
$$

(3) $n$ number of surrogates are generated and $L$ for each surrogate is computed;

(4) determine mean $L$ and SD $\sigma_{s}$ of these quantities;

(5) determine the measure of significance as proposed by Theiler et al. [84],

$$
S_{p s c}=\frac{\left|L-L_{s}\right|}{\sigma_{s}}
$$

\section{Number of Extrema for Unit Time}

The protocol of the number of extrema for unit time (NET) method involves the following steps:

(1) the number of extrema $N_{o}$ for unit time, $T_{o}$ of the given time series is determined and used as discriminating statistics;

(2) $n$ numbers of surrogate data sets are generated and the number of extremas for each surrogate set $N_{i}(i=1, \ldots n)$ are computed;

(3) the average NET $N_{s}$ and their SD $\sigma_{s}$ are determined and they are statistically discriminated by computing the significance

$$
S_{n e t}=\frac{\left|N_{o}-N_{s}\right|}{\sigma_{s}}
$$

Again, two types of surrogates are considered in our analysis, i.e. GS and PR surrogates. These are referred to as $S_{\text {netGS }}$ and $S_{\text {netPR }}$, respectively.

The reason to publish this as a separate report from our recent study on frequency domain measures [62] is that we obtained 
256-second HR time series data every $2 \mathrm{~h}$ for $24 \mathrm{~h}$ ( 12 segments) and used only those subjects who had at least 6 such segments for the day. Even when we strictly limited the data to four 256-second segments to truly reflect awake and sleep periods, we obtained very similar results. Then, we used the mean of these 125 -min segments, the mean of the first 6 segments, which mainyl reflected daytime, and the mean of the last 6 segments, which mainly reflected nighttime. We used each of these $256 \mathrm{~s}$ for the estimation of the LLE and all the above nonlinear measures. Due to the amount of time involved in the computation of these analyses for 4 nonlinear scores and the LLE (300 24-hour records $\times 72$ analyses), we limited it to 256-second segments. For longer data lengths, MED and LLE take up an enormous amount of computing time.

\section{Statistical Analysis}

First, we used a three-way ANOVA with paroxetine and nortriptyline as the grouping variables, sleep and awake as one within factor and pre- and posttreatment as the second repeated measure. Significant main or interaction effects were followed up with two-way ANOVA for repeated measures with the drug condition as the grouping factor and pre- and posttreatment ( 6 weeks) measures as the repeated measures for the mean of 12 epochs, and also day and night epochs (mean of 6 segments of $5 \mathrm{~min}$ each). The day and night epochs were obtained in two different ways. First, we used the average of the first 6 and the last 6 segments and, in addition, we also divided them into the mean of the first 4 (awake) segments and the mean of the 7th to 10th segment, which significantly reflected sleep. Significant effects were followed up by paired $t$ tests to compare patients separately for each drug condition. All tests were two-tailed and a probability value of 0.025 was accepted as significant as we performed two post hoc $t$ tests. Pearson's product-moment correlations were used to examine the relationship between HPV measures of interest and treatment effects. For those subjects who had data before and after placebo lead-in, the HPV measures were compared using ANOVAs

Table 2. Results of three-way ANOVA comparing the two drug conditions as the grouping factor and pre- and posttreatment and awake and sleep periods as repeated measures

\begin{tabular}{crll}
\hline & \multicolumn{1}{c}{$\mathrm{F}$} & d.f. & $\mathrm{p}$ \\
\hline $\mathrm{S}_{\mathrm{pscGS}}$ & & & \\
$\mathrm{S}$ & 15.69 & 1,33 & 0.0004 \\
$\mathrm{Sx}$ & 4.98 & 1,33 & 0.0326 \\
$\mathrm{~S}_{\text {netGS }}$ & & & \\
Tx & 7.38 & 1,33 & 0.0104 \\
$\mathrm{~S}$ & 15.55 & 1,33 & 0.0004 \\
$\mathrm{~S}_{\text {netPR }}$ & & & \\
Tx & 9.51 & 1,33 & 0.0041 \\
$\mathrm{~S}$ & 11.93 & 1,33 & 0.0015 \\
LLE & 4.66 & 1,23 & 0.04 \\
TS & & & \\
\hline
\end{tabular}

$\mathrm{x}=$ Group effect; $\mathrm{S}=$ awake vs. sleep effect; $\mathrm{T}=$ treatment (prevs. posteffect). for repeated measures. Pearson product-moment correlations were performed to examine the relationship between nonlinear measures and improvement in depression scores (HAMD) after treatment for either drug condition separately. As several correlations were performed, the significance level was set at $\mathrm{p}<0.025$.

We used only awake and sleep spectral powers in ULF, VLF, LF and $\mathrm{HF}$ bands for entering into step-wise regression analysis and discriminant function analysis along with the nonlinear measures to compare paroxetine and nortriptyline groups after treatment.

\section{Results}

Age was very similar between the paroxetine and nortriptyline groups. There were no significant group differences between baseline and after placebo lead-in periods for any of the HP variables. In fact, some of the values were almost identical. There was no gender effect for any of the analyses. For the awake and sleep periods, using the mean of 6 or 4 epochs has not made any significant changes in the results of ANOVA and t tests. Tables 1-3 show the results of three- and two-way ANOVAs along with results of $t$ tests in table 1 .

Table 3. Results of two-way ANOVA comparing the two drug conditions as the grouping factor and pre- and posttreatment awake and sleep periods separately

\begin{tabular}{|c|c|c|c|}
\hline & $\begin{array}{l}\text { Group } \\
\text { effect }\end{array}$ & $\begin{array}{l}\text { Treatment } \\
\text { effect }\end{array}$ & Interaction effect \\
\hline \multicolumn{4}{|l|}{ Awake } \\
\hline $\mathrm{S}_{\mathrm{pscPR}}$ & NS & NS & NS \\
\hline $\mathrm{S}_{\mathrm{pscGS}}$ & NS & NS & NS \\
\hline $\mathrm{S}_{\text {netPR }}$ & NS & NS & $\begin{array}{l}F=6.9 ; \text { d.f. }=1,40 \\
p=0.01\end{array}$ \\
\hline $\mathrm{S}_{\mathrm{netGS}}$ & NS & NS & $\begin{array}{l}F=4.1 ; \text { d.f. }=1,40 \\
p=0.05\end{array}$ \\
\hline MED & NS & NS & NS \\
\hline LLE & NS & NS & $\begin{array}{l}F=4.1 ; \text { d.f. }=1,23 \\
p=0.05\end{array}$ \\
\hline \multicolumn{4}{|l|}{ Sleep } \\
\hline $\mathrm{S}_{\mathrm{pscPR}}$ & NS & NS & NS \\
\hline $\mathrm{S}_{\mathrm{pscGS}}$ & NS & NS & NS \\
\hline $\mathrm{S}_{\text {netPR }}$ & NS & NS & $\begin{array}{l}F=5.6 ; \text { d.f. }=1,33 \\
p=0.02\end{array}$ \\
\hline $\mathrm{S}_{\text {netGS }}$ & NS & NS & $\begin{array}{l}F=8.93 ; \text { d.f. }=1,33 \\
p=0.005\end{array}$ \\
\hline MED & NS & NS & NS \\
\hline LLE & NS & $\begin{array}{l}F=9.7 \\
\text { d.f. }=1,28 \\
p=0.004\end{array}$ & NS \\
\hline
\end{tabular}


Table 1 shows the mean \pm SD of all HP variables with the significant differences between paroxetine and nortriptyline groups before and after treatment. We have chosen to do this for two reasons. Firstly, repeated-measures ANOVA has only shown significant decreases in $\mathrm{S}_{\text {netGS }}$ and $\mathrm{S}_{\text {netPR, }}$ and LLE for the nortriptyline condition. As there were fewer subjects for this comparison and as there were no significant differences between baseline (pre-) paroxetine and nortriptyline values for the above measures, we chose to present the results of the $t$ tests between post-paroxetine and post-nortriptyline values as there were more subjects in each group.

There were significant decreases in $S_{\text {netGS }}$ and $S_{\text {netPR, }}$ and LLE after nortriptyline treatment. The decrease in mean R-R interval and SD of R-R intervals was significant after nortriptyline, as expected.

\section{Discriminant Function Analysis}

When only spectral powers of HP after treatment were used, total and VLF power contributed significantly to the discrimination between the two treatments $(p<0.05)$. However, when all nonlinear and spectral variables are entered, only 12-epoch $\mathrm{S}_{\text {netGS }}$ and 6-epoch average awake LLE were the significant discriminators. Stepwise multiple regression analysis confirmed these findings (table 4).

\section{Correlations}

At baseline, before treatment, there were no significant correlations between nonlinear measures and HAMD. For the postparoxetine treatment condition, there were no significant correlations between nonlinear measures and the final HAMD score. There was a significant positive correlation between sleep LLE and HAMD $(r=0.54 ; p<$ 0.02 ) for post-nortriptyline condition.

\section{Discussion}

\section{Decreased LLE and Nonlinear Scores after \\ Nortriptyline}

The decrease in the LLE after nortriptyline is an important finding in this study as the LLE is a measure that is related to predictability, and a positive value usually indicates a degree of chaos. As described in the introduction, some of the nonlinear measures including the LLE are decreased in cardiac patients with poor prognosis. Thus, in a population that is already vulnerable, such as patients with ischemic heart disease and depression, the use of drugs like nortriptyline appears undesirable. As the evidence cited in the introduction also links the LLE to overall cardiac vagal function, any decrease in the LLE may be detrimental in vulnerable populations. On the other hand, paroxetine had no such effects. Similarly, there was a significant decrease in $S_{\text {netGS }}$ and $S_{\text {netPR only }}$ after nortriptyline. Nonlinearity measures basically provide information as to the deviation of the time series from linear surrogates. The interrelation or interaction of certain constants from Lorenz equations reveals the amount of linearity or nonlinearity in the system dynamics and this can be quantified as described above. Thus, the decrease in the interaction of some of these constants may have contributed to decreased nonlinearity scores, which most likely is due to the anticholinergic effect of nortriptyline. This is also in line with a much less significant antimuscarinic effect of paroxetine.

\section{Previous Frequency Domain Analyses and Measures of Symbolic Dynamics on this Data Set}

These analyses clearly showed a significantly more vagolytic effect for nortriptyline. However, it was interesting to note that paroxetine increased WC-100, a measure of symbolic dynamics, which indicates nonlinear complexity. Thus, the present findings are mostly in agreement with our previous report [62].
Table 4. Results of stepwise regression analysis for the variables that significantly discriminated paroxetine and nortriptyline groups at the end of treatment

\begin{tabular}{lllll}
\hline & Multiple r & $\mathrm{R}^{2}$ & Change & $\mathrm{p}$ \\
\hline S netGS (12-epoch mean) $_{\text {Awake LLE (6-epoch mean) }}$ & 0.76 & 0.58 & 0.58 & $<0.01$ \\
& 0.83 & 0.70 & 0.11 & $<0.05$ \\
\hline
\end{tabular}


Multiple Discriminant Function Analysis and Stepwise Regression Analysis

As described above, nonlinear measures were the most significant in discriminating posttreatment paroxetine and nortriptyline patients. This may be clinically very important because it is the nortriptyline group that had decreased variability and complexity of HP time series, which certainly is a risk factor for significant cardiovascular events.

\section{Paroxetine and Antimuscarinic Effects}

Compared with tricyclics, paroxetine has a weak affinity for muscarinic receptors, 15 -fold weaker than amitriptyline $[85,86]$. Fluoxetine and paroxetine did not produce any significant change in this variable. Pollock et al. [87] also reported that at therapeutic plasma concentrations, paroxetine is associated with approximately $1 / 5$ th of the anticholinergic effect of nortriptyline in older patients. The study by Owens et al. [88] also suggests that paroxetine does not have significant affinity for muscarinic receptors. Thus, all the above studies support a lack of significant antimuscarinic effects for paroxetine in this study group.

\section{Cardiac Autonomic Function, Nonlinear Measures} and Cardiovascular Mortality

Cole et al. [89] have recently shown that exercise recovery time is prolonged in people who are prone to have significant cardiovascular events which again relates impaired cardiac vagal function to a significant risk for cardiovascular mortality. Several studies have shown a decreased LLE probably related to decreased central vagal function, which may be related to significant cardiovascular events in patients with various neurological conditions [90-94]. It has also been well documented that a relative increase in cardiac sympathovagal balance can lead to serious ventricular arrhythmia $[95,96]$. Thus, any noninvasive measure that reflects cardiac vagal function is a valuable tool to study sudden cardiac death and poor prognosis in cardiac patients. Carney et al. [97] have shown an improvement in the parameters of HRV in depressed patients with myocardial infarction who underwent cognitive psychotherapy. Thus, the effectiveness of various treatment approaches should be evaluated in the context of cardiovascular effects and probably some of these new nonlinear measures may be of additional value. Some other measures, including measures of chaos, may prove very effective to identify other subtle changes in autonomic function.

\section{Correlation of HAMD with Posttreatment}

\section{Nonlinearity Measures and LLE}

It is interesting to note that the final HAMD (a lower score indicates better improvement) significantly correlated with the LLE, indicating that a decreased cardiac vagal function may be associated with a lower HAMD score, which again may indicate a stronger effect of nortriptyline in regard to its antimuscarinic effects in these patients. This may not suggest that the antimuscarinic effect itself is responsible for the treatment effect, but the overall antidepressant effect of the drug might be associated with a strong anticholinergic activity.

\section{Conclusions}

The findings of this study suggest a significant decrease in chaos of HP time series, probably due to the vagolytic effect of nortriptyline in patients with major depression and cardiac disease and thus between the two drugs; paroxetine may be a safer choice especially in the patients with myocardial infarction. This may be likely due to the weaker antimuscarinic effects of paroxetine.

\section{Limitations}

We had to exclude people in the placebo group (after placebo lead-in), as this was leaving us with fewer subjects for comparison. However, as mentioned, the values of various linear and nonlinear HRV measures were very similar and there were no significant differences between these two pre- and postplacebo periods. The measures of nonlinearity scores and LLE are relatively new and future prospective studies should validate their additional utility to the more traditional time and frequency domain measures. 


\section{References}

1 Dalack GW, Roose SP: Perspectives on the relationship between cardiovascular disease and affective disorder. J Clin Psychiatry 1990; 51(suppl):4-9.

2 Frasure-Smith N, Lesperance F, Talajic M: Depression and 18-month prognosis after myocardial infarction. Circulation 1995;91:9991005.

3 Carney RM, Freedland KE, Rich MW, Smith LJ, Jaffe AS: Ventricular tachycardia and psychiatric depression in patients with coronary artery disease. Am J Med 1993;95:23-28.

4 Carney RM, Sounders RD, Freedland KE, Stein P, Rich MW, Jaffe AS: Association of depression with reduced heart rate variability in coronary artery disease. Am J Cardiol 1995 76:562-564.

5 Carney RM, Freedland KE, Sheline YI, Weiss ES: Depression and coronary heart disease: A review for cardiologists. Clin Cardiol 1997;20: 196-200.

6 Musselman DL, Evans DL, Nemeroff CB: The relationship of depression to cardiovascular disease. Arch Gen Psychiatry 1998;55:580592.

7 Musselman DL, Evans DL, Nemeroff CB: The relationship of depression to cardiovascular disease. Arch Gen Psychiatry 1998;55:580592.

8 Everson SA, Roberts RE, Goldberg DE, Kaplan GA: Depressive symptoms and increased risk of stroke mortality over a 29-year period. Arch Intern Med 1998;158:1133-1138.

9 Horrobin DF, Bennett CN: Depression and bipolar disorder: Relationship to impaired fatty acid and phospholipid metabolism and to diabetes, cardiovascular disease, immunological abnormalities, cancer, ageing and osteoporosis. Possible candidate genes. Prostaglandins Leukot Essent Fatty Acids 1999;60:217-234.

10 Krittiyaphong R, Cascio WE, Light KC, Sheffield D, Golden RN, Finkel JB, Glekas G, Koch GG, Sheps DS: Heart rate variability in patients with coronary artery disease: Differences in patients with higher and lower depression scores. Psychosom Med 1997;59:231235.

11 Stein PK, Carney RM, Freedland KE, Skala JA, Jaffe AS, Kleiger RE, Rottman JN: Severe depression is associated with markedly reduced heart rate variability in patients with stable coronary heart disease. J Psychosom Res 2000;48: 493-500.

12 Yeragani VK: Major depression and long-term heart period variability. Depress Anxiety 2000; 12:51-52

13 Yeragani VK, Radhakrishna Rao KA, Smitha MR, Pohl R, Balon R, Srinivasan K: Diminished chaos of heart rate time series in patients with major depression. Biol Psychiatry 2002; 51:733-744.

14 Roose SP, Glassman AH, Atria E, Woodring S, Giardina EG, Bigger JT Jr: Cardiovascular effects of fluoxetine in depressed patients with heart disease. Am J Psychiatry 1998;155:660665.
15 Roose SP, Spatz E: Treating depression in patients with ischemic heart disease: Which agents are best to use and avoid? Drug Saf 1999;20:459-465.

16 Yeragani VK, Pohl R, Balon R, Ramesh C, Glitz D, Weinberg P, Merlos B: Effect of imipramine treatment on heart rate variability measures. Neuropsychobiology 1992;26:27-32.

17 Yeragani VK, Srinivasan K, Pohl R, Berger R, Balon R, Ramesh C, Berchou R: Effects of nortriptyline on heart rate variability in panic disorder patients: A preliminary study using power spectral analysis of heart rate. Neuropsychobiology 1994;29:1-7.

18 Yeragami VK, Jampala VC, Sobolewski E, Kay J, Igel G: Effects of paroxetine on heart period variability in patients with panic disorder: A study of Holter ECG records. Neuropsychobiology 1999;40:124-128.

19 Yeragani VK, Pohl R, Jampala VC, Balon R, Ramesh C, Srinivasan K: Effects of nortriptyline and paroxetine on QT variability in patients with panic disorder. Depress Anxiety 2000;11:126-130.

20 Rozanski A, Bairey CN, Krantz DS, Friedman J, Resse KJ, Morrell M, Hilton-Shalfen S, Hestrin L, Bietendorf J, Berman DS: Mental stress and the induction of silent myocardial ischemia in patients with coronary artery disease. N Engl J Med 1988;318:1005-1012.

21 Malik M, Camm AJ: Heart rate variability. Clin Cardiol 1990;13:570-576.

22 Malliani A, Pagani M, Lombardi F, Cerutti S: Cardiovascular neural regulation explored in the frequency domain. Circulation 1991;84: 482-492.

23 Yeragani VK, Nadella R, Hinze B, Yeragani S, Jampala VC: Nonlinear measures of heart period variability: Decreased measures of symbolic dynamics in patients with panic disorder. Depress Anxiety 2000;12:67-77.

24 Berger RD, Kasper EK, Baughman KL, Marban E, Calkins H, Tomaselli GF: Beat-to-beat QT interval variability: Novel evidence for repolarization lability in ischemic and nonischemic dilated cardiomyopathy. Circulation 1997;96:1557-1565

25 Yeragani VK, Srinivasan K, Vempati S, Pohl $\mathrm{R}$, Balon R: Fractal dimension of heart rate time series: An effective measure of autonomic function. J Appl Physiol 1993;75:2429-2438.

26 Yeragani VK, Nadella R, Hinze B, Yeragani S, Jampala VC: Nonlinear measures of heart period variability: Decreased measures of symbolic dynamics in patients with panic disorder. Depress Anxiety 2000;12:67-77.

27 Yeragani VK, Pohl R, Jampala VC, Balon R, Ramesh C, Srinivasan K: Increased QT variability in patients with panic disorder and depression. Psychiatry Res 2000;93:225-235.
28 Atiga WL, Fananpazir L, McAreavey D, Calkins H, Berger RD: Temporal repolarization lability in hypertrophic cardiomyopathy caused by beta-myosin heavy-chain gene mutations. Circulation 2000;101:1237-1242.

29 Ho KK, Moody GB, Peng CK, Mietus JE, Larson MG, Levy D, Goldberger AL: Predicting survival in heart failure case and control subjects by use of fully automated methods for deriving nonlinear and conventional indices of heart rate dynamics. Circulation 1997;96:842848

30 Kleiger RE, Miller JP, Bigger JT, Moss AJ: Decreased heart rate variability and its association with increased mortality after acute myocardial infarction. Am J Cardiol 1987;59:256262.

31 Bigger JT, Fleiss JL, Steinman R, Rolnitzky LM, Kleiger RE, Rottman JN: Frequency domain measures of heart period variability and mortality after myocardial infarction. Circulation 1992;85:164-171.

32 Kawachi I, Colditz GA, Ascherio A, Rimm EB, Giovanucci E, Stampfer MJ, Willett WC: Prospective study of phobic anxiety and risk of coronary heart disease in men. Circulation 1994;89:1992-1997.

33 Molgaard H, Sorensen KE, Bjerregard P: Attenuated 24-hour heart rate variability in apparently healthy subjects, subsequently suffering sudden cardiac death. Clin Auton Res 1991;1:233-237.

34 Akselrod S, Gordon D, Ubel FA, Shannon DC, Berger AC, Cohen RJ: Power spectrum analysis of heart rate fluctuation: A quantitative probe of beat-to-beat cardiovascular control. Science 1981;213:220-222.

35 Pomeranz B, Macaulay RJB, Caudill MA, Kutz I, Adam D, Gordon D, Kilborn KM, Berger AC, Shannon DC, Cohen RJ, Benson H: Assessment of autonomic function in humans by heart rate spectral analysis. Am J Physiol 1985; 248:H151-H153.

36 Lindqvist A, Jalonen J, Parviainen P, Antilla K, Laitinen LA: Effect of posture on thermally stimulated cardiovascular oscillations. Cardiovasc Res 1990;24:373-380.

37 Goldberger AL, West BJ: Fractals in physiology and medicine. Yale J Biol Med 1987;60: 421-435.

38 Glenny RW, Robertson HT, Yamashiro S, Bassingthwaighte JB: Application of fractal analysis to physiology. J Appl Physiol 1991;70: 2351-2367.

39 Guzzetti S, Signorini MG, Cogliati C, Mezzetti S, Porta A, Cerutti S, Malliani A: Non-linear dynamics and chaotic indices in heart rate variability of normal subjects and heart-transplanted patients. Cardiovasc Res 1996;31:441446.

40 Katz MJ: Fractals and the analysis of waveforms. Comput Biol Med 1988;18:145-156.

41 Kurths J, Voss A, Separin P, Witt A, Kleiner HJ, Wessel N: Quantitative analysis of heart rate variability. Chaos 1995;5:88-94. 
42 Lombardi F, Sandrone G, Mortara A, Torzillo D, Rovere MTL, Signorini MG, Cerutti S, Malliani A: Linear and nonlinear dynamics of heart rate variability after acute myocardial infarction with normal and reduced left ventricular ejection fraction. Am J Cardiol 1996;77:12831288.

43 Pincus SM, Gladstone IM, Ehrenkranz RA: A regulatory statistic for medical data analysis. J Clin Monit 1991;7:335-345.

44 Radhakrishna RKA, Dutt DN, Yeragani VK: Nonlinear measures of heart rate time series: Influence of posture and controlled breathing. Auton Neurosci 2000;83:148-158.

45 Radhakrishna RKA, Yeragani VK: Decreased measures of chaos and increased nonlinearity in patients with panic disorder. Auton Neurosci 2001;88:99-108.

46 Yeragani VK, Pohl R, Balon R, Berchou R, Srinivasan K, Glitz D: Effect of intravenous sodium lactate and isoproterenol infusions in normal controls and patients with panic disorder on nonlinear indices of heart rate variability. Psychiatry Res 2002;101:81-92.

47 Hagerman I, Berglund M, Lorin M, Nowak J, Sylven C: Chaos deterministic regulation of heart rate variability in time and frequency domains: Effects of autonomic blockade and exercise. Cardiovasc Res 1996;31:410-418.

48 Zwiener U, Hoyer D, Bauer R, Luthke B, Walter W, Schmidt K, Hallmeyer S, Kratzsch B, Eiselt M: Deterministic chaotic and periodic properties of heart rate and arterial fluctuations and their mediation in piglets. Cardiovasc Res 1996;31:455-465.

49 Poon CS, Merrill CK: Decrease of cardiac chaos in congestive heart failure. Nature 1997; 389:492-495.

50 Voss A, Hnatkova K, Wessel N, Kurths J, Sander A, Schirdewan A, Camm AJ, Malik M: Multiparametric analysis of heart rate variability used for risk stratification among survivors of acute myocardial infarction. Pacing Clin Electrophysiol 1998,21:186-192.

51 Makikallio TH, Hoiber S, Kober L, Torp-Pedersen C, Peng CK, Goldberger AL, Huikuri HV: Fractal analysis of heart rate dynamics as a predictor of mortality in patients with depressed left ventricular function after acute myocardial infarction. TRACE investigators. Trandolapril cardiac evaluation. Am J Cardio 1999;83:836-839.

52 Huikuri HV, Makakallio T, Airaksinen KE, Mitrani R, Castellanos A, Myerburg RJ: Measurement of heart rate variability: A clinical tool or a research toy? J Am Coll Cardiol 1999; 34:1878-1883.

53 Huikuri HV, Makikallio TH: Heart rate variability in ischemic heart disease. Auton Neurosci 2001;20:95-101

54 Glassman AH, Bigger JT: Cardiovascular effects of therapeutic doses of tricyclic antidepressants: A review. Arch Gen Psychiatry 1981;38:815-820.
55 Georgotas A, McCue RE, Friedman E, Cooper TB: Electrocardiographic effects of nortriptyline, phenelzine, and placebo under optimal treatment conditions. Am J Psychiatry 1987; 144:798-801.

56 Glassman AH, Roose SP, Giardina EV, Bigger JT: Cardiovascular effects of tricyclic antidepressants; in Meltzer HY (ed): Psychopharmacology, the Third Generation of Progress. New York, Raven Press, 1987.

57 McLeod DR, Hoehn-Saric R, Porges SW, Zimmerli WD: Effects of alprazolam and imipramine on parasympathetic cardiac control in patients with generalized anxiety disorder. Psychopharmacology (Berl) 1992;107:535-540.

58 Roose SP, Glassman AH: Cardiovascular effects of tricyclic antidepressants in depressed patients with and without heart disease. J Clin Psychiatry 1989;50(suppl):1-18.

59 Rechlin T, Claus D, Weiss M: Heart rate analysis in 24 patients treated with 150 mg amitriptyline per day. Psychopharmacology (Berl) 1994;116:110-114.

60 Tucker P, Adamson P, Miranda R Jr, Scarborough A, Williams D, Goff J, McClean H: Paroxetine increases heart rate variability in panic disorder. J Clin Psychopharmacol 1997; 17:370-376.

61 Roose SP, Laghrissi-Thode F, Kennedy JS, Nelson JC, Bigger JT Jr, Pollock BG, Gaffney A, Narayan M, Finkel MS, McCafferty J, Gergel I: Comparison of paroxetine and nortriptyline in depressed patients with ischemic heart disease. JAMA 1998;279:287-291.

62 Yeragani VK, Pesce V, Jayaraman A, Roose S: Major depression with ischemic heart disease: Effects of paroxetine and nortriptyline on longterm heart rate variability measures. Biol Psychiatry, in press.

63 Hamilton M: A rating scale for depression. J Neurol Neurosurg Psychiatry 1960;139:297305.

64 Huikuri HV, Niemela M, Ojala S, Rantala A, Ikaheimo MJ, Airaksinen KE: Circadian rhythms of frequency domain measures of heart rate variability in healthy subjects and patients with coronary artery disease. Effects of arousal and upright posture. Circulation 1994; 90:121-126.

65 Yeragani VK, Sobolewski E, Igel G, Johnson C, Jampala VC, Kay J, Hillman N, Yeragani S, Vempati S: Decreased heart period variability in patients with panic disorder: A study of Holter ECG records. Psychiatry Res 1998;78: 89-99.

66 Yeragani VK, Sobolewski E, Kay J, Jampala VC, Igel G: Effect of age on long-term heart rate variability. Cardiovasc Res 1997;35:35-42.

67 Yeragani VK, Sobolewski E, Jampala VC, Kay J, Yeragani S, Igel G: Fractal dimension and approximate entropy of heart period and heart rate: Awake versus sleep differences and methodological issues. Clin Sci (Lond) 1998;95: 295-301

68 Berger RD, Akselrod S, Gordon D, Cohen RJ: An efficient algorithm for spectral analysis of heart rate variability. IEEE Trans Biomed Engg 1986;33:900-904.
69 Takens F: Detecting strange attractors in turbulence; in Rand D, Young L (eds): Dynamical Systems and Turbulence. Lecture Notes on Mathematics. Berlin, Springer, vol 898, pp 366-381.

70 Grassberger P, Procaccia I: Measuring the strangeness of strange attractors. Physica D 1983;9:189-208.

71 Theiler J: Efficient algorithm for estimating the correlation dimension from a set of discrete points. Phys Rev A 1987;36:4456-4462.

72 Broomhead DS, King GP: Extracting qualitative dynamics from experimental data. Physica D 1986;20:217-236.

73 Mees AI, Rapp PE, Jennings LS: Singular value decomposition and embedding dimension. Phys Rev A 1987;37:340-346.

74 Kennel MB, Brown R, Abarbanel HD: Determining embedding dimension for phase-space reconstruction using a geometrical construction. Phys Rev A 1992;45:3403-3411.

75 Cao L: Practical method for determining the minimum embedding dimension of a scalar time series. Physica D 1997;110:43-50.

76 Rosenstein M, Collins JJ, De Luca CJ: A practical method for calculating largest Lyapunoy exponents from small data sets. Physica D 1993;65:117-134.

77 Sano M, Sawada Y: Measurement of the Lyapunov spectrum from a chaotic time series. Phys Rev Lett 1985;55:1082-1085.

78 Wolf A, Swift J, Swinney H, Vastano J: Determining Lyapunov exponents from a time series. Physica A 1985;16:285-317.

79 Sato S, Sano M, Sawada Y: Practical methods of measuring the generalized dimension and largest Lyapunov exponents in high-dimensional chaotic systems. Prog Theor Phys 1987; $77: 1-5$.

80 Zeng X, Eykholt R, Pielke RA: Estimating the Lyapunov-exponent spectrum from short time series of low precision. Phys Rev Lett 1991;66: 3229-3232.

81 Di Garbo A, Balocchi R, Chillemi S: Nonlinearity tests using the extrema of a time series. Int J Bifurcation Chaos 1998;8:1831-1838.

82 Ramani A, Grammaticos B, Bountis T: The Painleve property and singularity analysis of integrable and non-integrable systems. Phys Rep 1989;80:161-245.

83 Soong TT: Random Differential Equations in Science and Engineering. New York, Academic Press, 1973.

84 Theiler J, Eubank S, Longtin A, Galdrikian B, Farmer JD: Testing for nonlinearity in time series: The method of surrogate data. Physica D 1992; 58:77-94.

85 Thomas DR, Nelson DR, Johnson AM: Biochemical effects of the antidepressant paroxetine, a specific 5-hydroxytryptamine uptake inhibitor. Psychopharmacology (Berl) 1987;93: 193-200.

86 Johnson AM: An overview of the animal pharmacology of paroxetine. Acta Psychiatr Scand Suppl 1989;350:14-20.

Yeragani/Roose/Mallavarapu/

Radhakrishna/Pesce 
87 Pollock BG, Mulsant BH, Nebes R, Kirshner MA, Begley AE, Mazumdar SA, Reynolds CF: Serum anticholinergicity in elderly depressed patients treated with paroxetine or nortriptyline. Am J Psychiatry 1998;158:1110-1112.

88 Owens MJ, Morgan WN, Plott SJ, Nemeroff $\mathrm{CB}$ : Neurotransmitter receptor and transporter binding profile of antidepressants and their metabolites. J Pharmacol Exp Ther 1997;283: 1305-1322.

89 Cole CR, Blackstone EH, Pashkow FJ, Snader CE, Lauer MS: Heart rate recovery immediately after exercise as a predictor of mortality. $\mathrm{N}$ Engl J Med 1999;341:1351-1357.
90 Faustmann PM, Ganz RE: Central cardioautonomic disorganization in interictal states of epilepsy detected by phase-space analysis. Int J Neurosci 1994;78:43-47.

91 Ganz RE, Weibels G, Stacker KH, Faustmann PM, Zimmermann CW: The Lyapunov exponents of heart rate dynamics as a sensitive marker of central autonomic organization: An exemplary study of early multiple sclerosis. Int $\mathrm{J}$ Neurosci 1993;71:29-36.

92 Monge-Argiles JA, Palacios-Ortego F, Vila-Sobrino JA, Matais-Guiu J: Heart rate variability in multiple sclerosis during a stable phase. Acta Neurol Scand 1998;97:86-92.

93 Monge-Argiles JA, Palacios Ortega F, Vila Sobrino JA, Bautista Prados J, Perez Vicente JA, Morales Ortiz A, Palao Sanchez A: Brain stem lesions decrease heart rate variability. Neurologia 2000;15:158-163.
94 Nordenbo AM, Boesen F, Andersen EB: Cardiovascular autonomic function in multiple sclerosis. J Auton Nerv Syst 1989;26:77-84.

95 Tomaselli GF, Buckelman DJ, Calkins HG Sudden cardiac death in heart failure. The role of abnormal repolarization. Circulation 1994; 90:2534-2539.

96 Binah O, Rosen MR: Mechanisms of ventricular arrhythmias. Circulation 1992;85(1 suppl): I25-I31.

97 Carney RM, Freedland KE, Stein PK, Skala JA, Hoffman P, Jaffe AS: Change in heart rate variability during treatment for depression in patients with coronary heart disease. Psychosom Med 2000;62:639-647. 